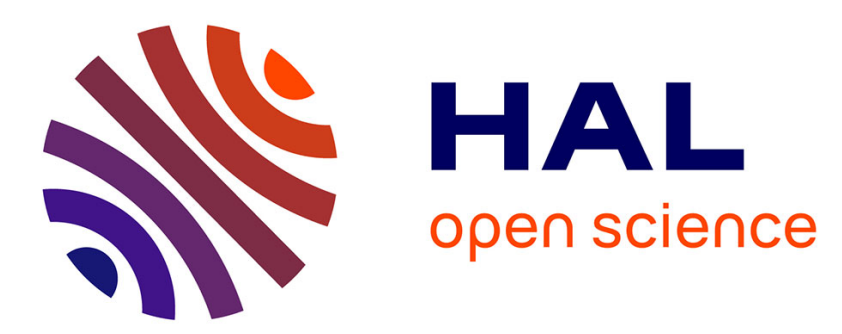

\title{
Muscimol Diffusion after Intracerebral Microinjections: A Reevaluation Based on Electrophysiological and Autoradiographic Quantifications
}

\author{
Jean-Marc Edeline, Bernard Hars, Elizabeth Hennevin, Nathalie Cotillon
}

\section{- To cite this version:}

Jean-Marc Edeline, Bernard Hars, Elizabeth Hennevin, Nathalie Cotillon. Muscimol Diffusion after Intracerebral Microinjections: A Reevaluation Based on Electrophysiological and Autoradiographic Quantifications. Neurobiology of Learning and Memory, 2002, 78 (1), pp.100 - 124. 10.1006/nlme.2001.4035 . hal-02398902

\section{HAL Id: hal-02398902 \\ https://hal.science/hal-02398902}

Submitted on 11 Dec 2019

HAL is a multi-disciplinary open access archive for the deposit and dissemination of scientific research documents, whether they are published or not. The documents may come from teaching and research institutions in France or abroad, or from public or private research centers.
L'archive ouverte pluridisciplinaire HAL, est destinée au dépôt et à la diffusion de documents scientifiques de niveau recherche, publiés ou non, émanant des établissements d'enseignement et de recherche français ou étrangers, des laboratoires publics ou privés. 


\title{
Muscimol Diffusion after Intracerebral Microinjections: A Reevaluation Based on Electrophysiological and Autoradiographic Quantifications
}

\author{
Jean-Marc Edeline, Bernard Hars, Elizabeth Hennevin, and Nathalie Cotillon \\ Laboratoire de Neurobiologie de l'Apprentissage, de la Mémoire et de la Communication, \\ UMR CNRS 8620, Université Paris-Sud, 91405 Orsay, France
}

Published online March 14, 2002

\begin{abstract}
Intracerebral muscimol injection is widely used to inactivate discrete brain structures during behavioral tasks. However, little effort has been made to quantify the extent of muscimol diffusion. The authors report here electrophysiological and autoradiographic results obtained after muscimol injection $(1 \mu \mathrm{g} / \mu \mathrm{l})$ either into the nucleus basalis magnocellularis $(0.1-0.4 \mu \mathrm{l})$ or into the thalamic reticular nucleus (RE, 0.05-0.1 $\mu$ l). In 52 rats, multiunit recordings were collected either in the RE or in the auditory thalamus during the $2 \mathrm{~h}$ following muscimol injection. Decreases in neuronal activity were observed up to $3 \mathrm{~mm}$ from the injection site; their time of occurrence was a function of the distance between the injection and recording sites. Because these decreases cannot be explained by physiological effects, they likely reflected muscimol diffusion up to the recording sites. Autoradiographic studies involved 25 rats and different experimental conditions. Optical density (OD) measures indicated that after a survival time of $15 \mathrm{~min}$, a $0.05-\mu \mathrm{l}$ injection produced a labeled area of $5.25 \mathrm{~mm}^{2}$ at the injection site and a rostrocaudal labeling of 1.7 $\mathrm{mm}$. Increasing the survival time to $60 \mathrm{~min}$, or increasing the injected volume to $0.1 \mu \mathrm{l}$, systematically led to a larger labeled area at the injection site $\left(8-12 \mathrm{~mm}^{2}\right)$ and to a larger rostrocaudal diffusion $(2.0-2.5 \mathrm{~mm})$. Direct quantifications of radioactivity by a high-resolution radioimager validated the OD measures and even indicated a larger muscimol diffusion (up to $3.25 \mathrm{~mm}$ ). Thus, these data point out that muscimol diffusion after intracerebral microinjection is larger than usually supposed. The relationships between these results and those obtained in behavioral studies are discussed. ๑ 2002 Elsevier Science (USA)
\end{abstract}

We gratefully acknowledge Françoise Tardieux (Biospace Mesures), who kindly quantified the brain sections with the $\beta$-Imager 2000. We thank I. Delamanche for assistance in histology and autoradiography, P. Lanièce for giving us the first opportunity to use a radioimager, and R. Mastrippolito for calculation of the theoretical muscimol diffusion. Special thanks go to Jessica Dubois for detailed explanations on the laws of Fickian diffusion. N.C. was supported by a doctoral fellowship from the MENESR.

Address correspondence and reprint requests to Jean-Marc Edeline, NAMC, UMR 8620, Université ParisSud, Bât 446, 91405 Orsay cedex, France. Fax: 33-1-69-15-77-26. E-mail: Jean-Marc.Edeline@ibaic.u-psud.fr. 
Key Words: intracerebral microinjection; muscimol; electrophysiological recordings; autoradiography; radioimager; drug diffusion; local inactivation; rat.

\section{INTRODUCTION}

Over the past decade, an increasing number of studies have used intracerebral microinjection of muscimol to reversibly inactivate localized brain areas. This method has been employed particularly in behavioral studies to explore the role of discrete brain regions in different learning tasks (e.g., Dudchenko \& Sarter, 1991; Holt \& Maren, 1999; Meloni \& Davis, 1999; Muir, Robbins, \& Everitt, 1992; Muller, Corodimas, Fridel, \& LeDoux, 1997; Oshiro, Bushnell, \& Chiba, 2000; Pang, Williams, Egeth, \& Olton, 1993; Paolini, Cotterill, Bairaktaris, \& Clark, 1998; Poremba \& Gabriel, 1999; Ramnani \& Yeo, 1996; Welsh \& Harvey, 1991; Wilensky, Schafe, \& LeDoux, 1999, 2000). Indeed, injection of the $\mathrm{GABA}_{\mathrm{A}}$ agonist muscimol presents several advantages. Contrary to blockers of sodium channels (e.g., tetrodotoxin) or to local anesthetics (e.g., lidocaine), which prevent the occurrence of action potentials from both local neurons and fibers of passage (Hilles, 1966, 1977; Ritchie, 1979), muscimol only inactivates the activity of local neurons. Its behavioral effects can be observed a few minutes after injection, and they can last up to several hours, thereby allowing extensive behavioral tests after injection (for a review, see Martin \& Ghez, 1999).

Our initial goal was to evaluate the effects of inactivation of nucleus basalis magnocellularis (NBM) neurons on neuronal activity in the auditory cortex. Given the large number of studies that had used muscimol injection, we thought that its spread of diffusion was limited enough to allow unambiguous interpretation of the observed effects. However, the electrophysiological results obtained were puzzling and led us to suspect a muscimol diffusion up to the thalamic reticular nucleus (RE). To clear up the matter, we decided to perform electrophysiological and autoradiographic experiments aiming at determining the extent of muscimol diffusion.

For electrophysiologists, a potent way of distinguishing between real physiological effects and effects due to diffusion of an inactivating agent is to inject the drug in a structure A and to record neuronal activity in a structure B that receives inhibitory monosynaptic projections from A. Logically, the removal of inhibitory inputs from A should lead to increased activity in B. Reduction of activity in B can be viewed as evidence for a direct spread of the inactivating agent from A to B. Using this rationale, two series of electrophysiological experiments were conducted. In the first ones, muscimol was injected into the NBM and neuronal activity was recorded in the RE. It is known that NBM cholinergic and GABAergic neurons send monosynaptic projections to the RE (Jourdain, Semba, \& Fibiger, 1989), that acetylcholine hyperpolarizes RE cells (Ben-Ari, Dingledine, Kanazawa, \& Kelly, 1976; McCormick \& Prince, 1986), and that NBM stimulation suppresses RE activity (Pinault \& Deschenes, 1992). Therefore, inactivation of the NBM should logically lead to increased neuronal activity in the RE. In the second series, muscimol was injected into the auditory sector of the RE and recordings were collected in the medial geniculate body (MGB). The RE is exclusively composed of GABAergic cells that send a monosynaptic input to thalamic relay neurons (Houser, Vaughan, Barber, \& Roberts, 1980; Jones, 1975; Pinault \& Deschenes, 1998) including 
MGB cells (Crabtree, 1998; Montero, 1983). Therefore, inactivation of the auditory sector of the RE should logically lead to increased neuronal activity in the MGB.

Autoradiographic experiments were also performed to complement the electrophysiological data. Tritium-labeled muscimol was injected either into the NBM or into the RE, and the extent of muscimol diffusion was estimated based on the quantification of the areas labeled along the rostrocaudal axis. Autoradiographic data were quantified by both classical optical density measures and direct measures of the radioactivity using a radioimager (RI).

\section{MATERIALS AND METHODS}

\section{Animal Preparation and Injection Technique in Electrophysiological and Autoradiographic Studies}

Adult Sprague-Dawley rats (280-320 g) were anesthetized (urethane, $1.5 \mathrm{~g} / \mathrm{kg}$, supplemented by $0.5 \mathrm{~g} / \mathrm{kg}$ when needed) and placed in a stereotaxic frame. After the scalp of each animal was opened, a local anesthetic (Xylocaine, 2\%) was liberally infiltrated into the wound. The body temperature was maintained between 36 and $37^{\circ} \mathrm{C}$ by a heating pad. Three silver ball electrodes $(400 \mu \mathrm{m})$ were inserted between the bone and the dura; one was used as a reference during the recording sessions, and the other two were placed over the frontal and parietal cortex and served to monitor the electroencephalogram (EEG). All procedures were in accordance with the European legislation on animal experimentation.

Burr holes were made over the injection sites. An assembly composed of a 26-gauge stainless steel guide tube and of two $50-\mu \mathrm{m}$ tungsten electrodes $(0.5 \mathrm{M} \Omega$ at $1 \mathrm{kHz})$ glued to both sides of the tube and protruding from the tube by $1 \mathrm{~mm}$ was slowly lowered under electrophysiological control. Correct placement in the target structures was based on (a) EEG desynchronization in response to low-intensity stimulation $(<150 \mu \mathrm{A})$ between the two electrodes for placements in the NBM and (b) high-frequency bursting activity and short latency $(<20 \mathrm{~ms})$ tone-evoked responses for placements in the auditory RE (Cotillon \& Edeline, 2000; Shosaku \& Sumitomo, 1983).

Muscimol was dissolved in sterile isotonic saline $45 \mathrm{~min}$ before injection. It was injected through a 33-gauge stainless steel cannula connected to a 0.5 - $\mu$ l Hamilton syringe via a short $(30-\mathrm{cm})$ catheter. The tip of the cannula extended $500 \mu \mathrm{m}$ beyond the extremity of the guide tube. Injection was always performed at a rate of $0.1 \mu \mathrm{l} / \mathrm{min}$. The concentration of muscimol $(1 \mu \mathrm{g} / 1 \mu \mathrm{l}, 8.7 \mathrm{mM})$ and the volume injected $(0.05-0.40 \mu \mathrm{l})$ were in the range of those used in a number of studies (comparable concentrations were used in Beninger, Ingles, Mackenzie, Jhamandas, \& Boegman, 1992; Holt \& Maren, 1999; Muller et al., 1997; Nagahara \& McGaugh, 1992; Nagahara, Brioni, \& McGaugh, 1992; Smith, Beninger, Mallet, Jhamandas, \& Boegman, 1994; and Wilensky et al., 1999, 2000; in most of these studies, the injected volume was $0.5 \mu \mathrm{l}$ ).

\section{Electrophysiological Experiments}

Recording procedures. In Experiment 1, $0.4 \mu \mathrm{l}$ of muscimol was injected into the NBM (1.8 $\mathrm{mm}$ posterior from bregma, $3 \mathrm{~mm}$ lateral, $6.5-8.0 \mathrm{~mm}$ below pia), and multiunit activity was recorded in the RE, either in its non-auditory sectors (from -2.3 to -3.3 / 
TABLE 1

Electrophysiological Studies

\begin{tabular}{lcccc}
\hline & Number of animals & Site of injection & Recording site & Number of recordings \\
\hline Experiment 1 & 6 & NBM $(0.4 \mu \mathrm{l})$ & Non-auditory RE & $n=11$ \\
& 9 & NBM $(0.4 \mu \mathrm{l})$ & Auditory RE & $n=17$ \\
Experiment 2 & 14 & Auditory RE $(0.1 \mu \mathrm{l})$ & Auditory thalamus & $n=28$ \\
& 23 & Auditory RE $(0.05 \mu \mathrm{l})$ & Auditory thalamus & $n=46$ \\
\hline
\end{tabular}

Note. Volumes are in parentheses. NBM, nucleus basalis magnocellularis; RE, reticular nucleus.

bregma) or in its auditory sector (from -3.3 to $-3.8 /$ bregma) (see Rouiller \& Welker, 1991). In Experiment 2, $0.1 \mu \mathrm{l}$ of muscimol was injected into the auditory RE, and multiunit activity was recorded in the MGB from -4.8 to $-6.3 /$ bregma. Table 1 presents the number of recordings collected in these two experiments.

The recording electrodes were $50-\mu \mathrm{m}$ tungsten wires $(\sim 0.5 \mathrm{M} \Omega$ at $1 \mathrm{kHz})$. Two electrodes, spaced by 200 to $300 \mu \mathrm{m}$ in the rostrocaudal axis, were slowly lowered either in the RE or in the MGB under electrophysiological control. Cellular responses to pure tone bursts were used to ensure correct placement in the auditory sector of the RE or in the MGB. Typical high-frequency bursting activity was used as an indication of correct placement in non-auditory RE (Pinault \& Deschenes, 1992). The signal coming from the electrodes was amplified (AM System, gain 10,000), filtered (bandpass 0.6-10.0 kHz), displayed on an oscilloscope, and sent to a voltage window discriminator to select the largest spikes (signal-to-noise ratio $\sim 3: 1$ ). The TTL pulses generated by the voltage window discriminator were sent to the acquisition board (PClab, PCL 720) of a laboratory microcomputer.

Experimental protocol. The cannula was inserted into the guide tube $2 \mathrm{~mm}$ above the target structure, but it was still kept away from the extremity of the tube. It was gently pushed to its final placement (with the tip extending $500 \mu \mathrm{m}$ beyond the tube) at the end of the control preinjection period (see below). In the two experiments, 10-trial blocks of tone presentations $(1-25 \mathrm{kHz}, 70-80 \mathrm{~dB}, 1-\mathrm{s}$ duration) were delivered every $5 \mathrm{~min}$ while recordings were collected either in the RE or in the MGB. On-line rasters and histograms (10-ms bin) corresponding to each recording electrode were displayed by 10-trial blocks. Recordings were collected for at least 35 min before muscimol injection (control period) and for up to $2 \mathrm{~h}$ after injection (post-injection period).

Histology. At the end of the recording session, 1\% Alcian blue in $0.1 \mu$ l of saline was injected at the same site as was muscimol. Each animal was given an overdose of nembutal $(200 \mathrm{mg} / \mathrm{kg})$, and the brain was rapidly removed from the calvarium. Brains were stored for at least 1 week in buffered formalin (10\% in phosphate buffer, $\mathrm{pH}$ 7.4) and then were placed in $30 \%$ sucrose-formalin until they sank. They were cut on a freezing microtome (50- $\mu \mathrm{m}$ thick serial coronal sections). The sections were stained with cresyl violet for Nissl preparation and were subsequently examined for determination of the injection site (in NBM or in RE) and of the recording electrode placements (in RE or in MGB). The antero-posterior distance between the recording site and the injection site was determined, and the absolute distance between the two sites, $d$, was computed by the following formula: 


$$
d=\sqrt{\left[\left(x_{\mathrm{rec}}-x_{\mathrm{inj}}\right)^{2}+\left(y_{\mathrm{rec}}-y_{\mathrm{inj}}\right)^{2}+\left(z_{\mathrm{rec}}-z_{\mathrm{inj}}\right)^{2}\right]}
$$

where $x, y$, and $z$ represent the anteriority $(x)$, laterality $(y)$, and verticality $(z)$ of the recording ( ${ }_{\text {rec }}$ ) and injection (inj) sites, respectively. Determination of the coordinates of the injection and recording sites was done blindly with regard to the electrophysiological results. Because no correction factor was used to take into account the tissue shrinkage, all of the distances provided in the results might be underestimated by about $10 \%$.

Data analysis. Standard peristimulus time histograms (10-ms bin) were built by blocks of 10 trials. Spontaneous activity was quantified during the $500 \mathrm{~ms}$ preceding each tone presentation. The "on" tone-evoked response was analyzed using, for each recording, the time window that was most appropriate to quantify the response $(0-30,0-50$, or $0-100$ $\mathrm{ms}$ after tone onset). Spontaneous and evoked activities recorded after muscimol injection were averaged in successive 15-min blocks and were compared to the mean values obtained during the 30-min preinjection period using paired $t$ tests.

\section{Autoradiographic Experiments}

Because the local and national laws do not allow manipulation of $\left[{ }^{3} \mathrm{H}\right]$ drugs in the same experimental room as the one used for electrophysiological recordings, the autoradiographic analyses were not performed in the same animals as those involved in electrophysiological experiments.

Experimental procedures. $\quad$ Labeled muscimol ([ $\left.{ }^{3} \mathrm{H}\right]$ muscimol, $1 \mu \mathrm{Ci} / \mu \mathrm{l}, 14 \mathrm{Ci} / \mathrm{mmol}$, Amersham, UK) was used. The exact volume of $\left[{ }^{3} \mathrm{H}\right]$ muscimol to be injected was backfilled into the cannula. The cannula was inserted into the guide tube $2 \mathrm{~mm}$ above the target structure. It was pushed to its final placement when the final stereotaxic coordinates were reached and met the electrophysiological criteria.

Labeled muscimol was injected, and after a prescribed time interval (see below) an overdose of nembutal $(200 \mathrm{mg} / \mathrm{kg}$ ) was given. The animal was decapitated, and the brain was quickly removed from the calvarium and immediately frozen in chilled isopentane $\left(-40^{\circ} \mathrm{C}\right)$. The brain was then kept at $-80^{\circ} \mathrm{C}$ until being sliced on a freezing microtome. Three adjacent sections (20- $\mu \mathrm{m}$ thickness) were directly mounted onto glass slides every $250 \mu \mathrm{m}$. They provided three sets of sections; the first set was used for Nissl staining to localize the brain structures, the second was used for autoradiographic quantification using optical density (OD) measurements, and the third was used for direct quantification of the radioactivity by a radioimager.

Protocol. Table 2 summarizes the six experimental groups used. These groups were designed to investigate the effects of the following factors: (a) site of injection, (b) mode of injection, and (c) time of survival after injection. The effect of injection site was estimated by comparing the spreads of diffusion of $0.1 \mu \mathrm{l}$ of muscimol injected into the NBM versus into the RE (comparison between Groups 2 and 3). The effect of injection mode was evaluated by comparing the spreads of diffusion observed after $0.1-\mu$ l injection performed via a motorized pump (rate of $0.1 \mu \mathrm{l} / \mathrm{min}$, Harvard syringe pump, Model 2) versus performed by hand over 1 min (comparison between Groups 3 and 4). The effect of time was assessed by comparing the spreads of diffusion obtained 15 min versus 
TABLE 2

Autoradiographic Studies

\begin{tabular}{ccccccc}
\hline & $\begin{array}{c}\text { Number of } \\
\text { animals }\end{array}$ & $\begin{array}{c}\text { Site of } \\
\text { injection }\end{array}$ & $\begin{array}{c}\text { Volume } \\
\text { injected } \\
(\mu \mathrm{l})\end{array}$ & $\begin{array}{c}\text { Radioactivity } \\
\text { injected } \\
(\mu \mathrm{Ci})\end{array}$ & $\begin{array}{c}\text { Mode of } \\
\text { injection }\end{array}$ & $\begin{array}{c}\text { Time of survival } \\
\text { after injection } \\
(\mathrm{min})\end{array}$ \\
\hline Group 1 & 5 & $\mathrm{NBM}$ & 0.4 & 0.1 & manual & 120 \\
Group 2 & 5 & $\mathrm{NBM}$ & 0.1 & 0.1 & pump & 60 \\
Group 3 & 4 & $\mathrm{RE}$ & 0.1 & 0.1 & pump & 60 \\
Group 4 & 5 & $\mathrm{RE}$ & 0.1 & 0.1 & manual & 60 \\
Group 5 & 3 & $\mathrm{RE}$ & 0.05 & 0.05 & manual & 60 \\
Group 6 & 3 & $\mathrm{RE}$ & 0.05 & 0.05 & manual & 15 \\
\hline
\end{tabular}

Note. NBM, nucleus basalis magnocellularis; RE, reticular nucleus.

obtained $60 \mathrm{~min}$ after $0.05-\mu \mathrm{l}$ injection into the RE (comparison between Groups 5 and 6). Lastly, rats in Group 1 received $0.4 \mu \mathrm{l}$ of muscimol into the NBM and were sacrificed $2 \mathrm{~h}$ after injection. This group was used (a) because part of the electrophysiological data was obtained after $0.4-\mu \mathrm{l}$ muscimol injection and (b) because all neuronal recordings were collected up to $120 \mathrm{~min}$ after injection. For this group, $0.1 \mu \mathrm{l}$ of $\left[{ }^{3} \mathrm{H}\right]$ muscimol was dissolved in $0.3 \mu \mathrm{l}$ of non-labeled muscimol to avoid film saturation. Thus, rats in this group received the same amount of radioactive molecules as did those in groups injected with $0.1 \mu \mathrm{l}$ of $\left[{ }^{3} \mathrm{H}\right]$ muscimol, but the injection volume was four times larger and the survival time was twice as long.

\section{Data Analysis}

Autoradiogram quantification. The slides were apposed to X-ray films (Amersham Hyperfilm for $\left[{ }^{3} \mathrm{H}\right]$ muscimol) along with $\left[{ }^{3} \mathrm{H}\right]$ standards (Amersham) for 4 weeks. Autoradiograms of individual brain sections were digitized (Umax 2400, 1200 dpi, 16 bits precision), and the images were quantified with the VisiLog software package (version 5.2, Noesis, France). Four parameters were derived from each labeled zone on every section: (a) the optical density, (b) the width, (c) the height, and (d) the surface area. The width and the height represented the smallest diameter (usually oriented in the horizontal direction) and the largest diameter (usually oriented in the vertical direction), respectively, of the smallest ellipse matching the labeled area. (This was a conservative estimate because the ellipse fitted entirely inside the labeled area.) The quantification of the area was based not on the surface of this ellipse but rather on a careful drawing of the labeled area. In addition, for each animal, the rostrocaudal extent of diffusion was estimated by measuring the distance between the injection track (determined from Nissl stained sections) and the last section (in the caudal direction) on which the image analysis system detected labeling above film background level. Radioactivity values were generated from the OD measures using autoradiographic $\left[{ }^{3} \mathrm{H}\right]$ micro-scales (Amersham, RPA 506 and 507).

Measures from rats of a given group were pooled together, and between-groups comparisons were made with analyses of variance and unpaired $t$ tests. 
Quantification by a radioimager. Direct quantification of the radioactivity was carried out to verify the limits of the rostrocaudal diffusion previously estimated by OD measures. A radioimager $(\mathrm{RI})$ is a real-time position sensitive detector developed to image and to quantify low-activity beta sources with a high spatial resolution (for descriptions, see Charpak, Dominik, \& Zaganidis, 1989; Charpak, Imrie, et al., 1989; Lanièce et al., 1998). The three main advantages of RIs are (a) their capability to image samples labeled with ${ }^{3} \mathrm{H}$ about 150 times faster than emulsions or films, (b) their capability to provide absolute and accurate radioactivity quantification over a wide dynamic range, and (c) a spatial resolution ranging from 200 to $15 \mu \mathrm{m}$ for high-resolution RIs.

We used a large-surface RI ( $\beta$-Imager 2000, Biospace Mesures, France), directly derived from multi-wire proportional counting (MWPC) devices used in the high energies (Charpak, Imrie, et al., 1989). Using a parallel plate avalanche chamber (PPAC) filled with a gas mixture (Argon-TEA), its detection threshold for tritium is $0.007 \mathrm{cpm} / \mathrm{mm}^{2}$. Its large surface of detection $(20 \times 25 \mathrm{~cm})$ allowed quantification of up to 15 glass slides simultaneously (each slide included up to 4 brain sections) with a resolution of 100 to $150 \mu \mathrm{m}$. A total of 141 brain sections from 25 animals were analyzed (exposure time: $21 \mathrm{~h}$ ). These sections corresponded to the last sections around which labeling disappeared according to OD measures.

\section{RESULTS}

\section{Electrophysiological Results}

\section{Effects of Muscimol at the Injection Site (0.1 $\mu$ l injected into the NBM)}

In 6 animals, 10 recordings were collected after $0.1-\mu$ l saline injection and then after $0.1-\mu l$ muscimol injection into the NBM (the two injections were made at least $2.5 \mathrm{~h}$ apart). The recordings were from the two electrodes glued to the guide tube $(500 \mu \mathrm{m}$ from the tip of the cannula). As shown in Fig. 1, 2 min after saline injection, spontaneous activity was decreased by $40 \%$ of the mean preinjection value, $t(9)=2.53, p=.032$. This decrease was still significant $10 \mathrm{~min}$ after injection, $t(9)=2.87, p=.012$; thereafter, the values no longer differed from the control level, $p>.10$ at all time points. On the other hand, 2 min after muscimol injection, spontaneous activity was already decreased by $80 \%$. From $25 \mathrm{~min}$ up to $2 \mathrm{~h}$ after injection, it was almost totally suppressed.

Thus, at immediate vicinity of the injection site, neuronal activity was rapidly and strongly suppressed after muscimol injection, whereas it was transiently and moderately decreased after saline injection. We may suspect that the decreased neuronal activity after saline injection resulted mainly from slight mechanical movements that occurred when the cannula was pushed at the extremity of the guide tube and from mechanical perturbation due to the injected volume.

\section{Muscimol Injection $(0.4 \mu l)$ in the NBM: Recording in the RE}

For 6 animals, electrophysiological recordings $(n=11)$ were collected in non-auditory sectors of the RE. The mean rostrocaudal distance between the injection site and the recording site was $0.59 \pm 0.12 \mathrm{~mm}$ (range : $0.2-1.5$ ). The mean absolute distance was $1.80 \pm 0.23 \mathrm{~mm}$ (range : 1.0-3.3). As shown in Fig. 2A, spontaneous activity began to 


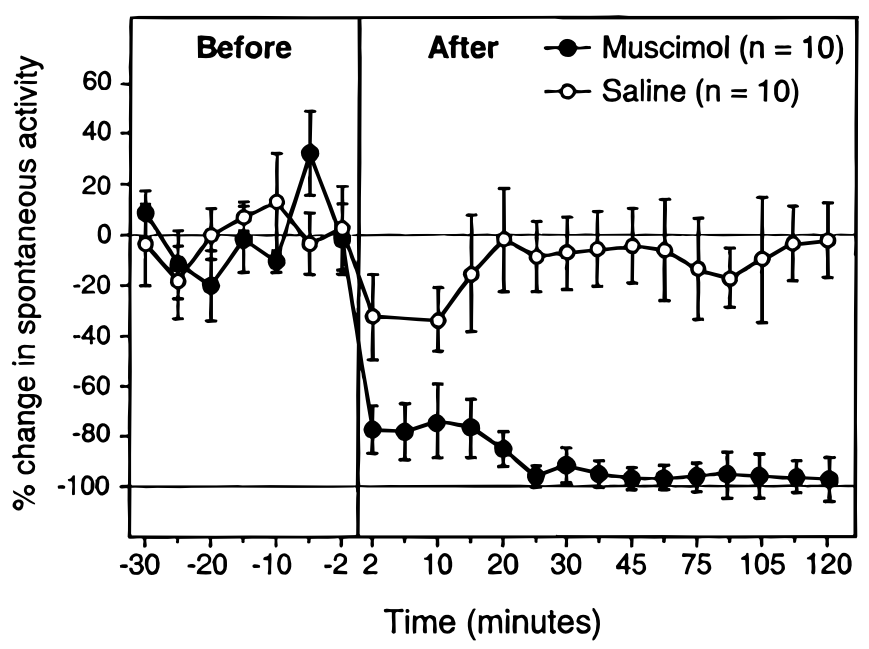

FIG. 1. Percent changes in neuronal activity at the injection site after muscimol or saline injection. Neuronal recordings were collected by two tungsten electrodes glued to the sides of the guide tube (500 $\mu \mathrm{m}$ from the tip of the cannula). Spontaneous activity was recorded every 5 min during the $30 \mathrm{~min}$ preceding and the $120 \mathrm{~min}$ following a $0.1-\mu \mathrm{l}$ injection of saline or muscimol into the nucleus basalis magnocellularis. Each point represents the mean value ( \pm SEM) obtained over the 10 recordings. Spontaneous activity fell to less than $20 \%$ of its initial value $2 \mathrm{~min}$ after muscimol injection. From $25 \mathrm{~min}$ post-injection until the end of the experiment, spontaneous activity was almost totally suppressed. By contrast, spontaneous activity was decreased by only $40 \%$ during the first $10 \mathrm{~min}$ following saline injection. Then, it rapidly recovered; from 15 min post-injection, it no longer significantly differed from the preinjection value.

decrease shortly after injection; this decrease became significant at 10 min post-injection, $t(10)=2.25, p<.05$. From $40 \mathrm{~min}$ up to $2 \mathrm{~h}$ after injection, spontaneous activity was totally suppressed.

For 9 animals, neuronal recordings $(n=17)$ were collected in the auditory sector of the RE. The mean rostrocaudal distance between the injection and recording sites was $1.13 \pm 0.23 \mathrm{~mm}$ (range : 0.4-2.0). The mean absolute distance was $2.82 \pm 0.16 \mathrm{~mm}$ (range : 1.2-3.5). As shown in Fig. 2B, spontaneous activity progressively decreased during the post-injection period; this decrease reached significance 30 to $45 \mathrm{~min}$ after injection, $t(16)=2.32, p=.04$.

As shown in Fig. 2C, over the whole set of 28 recordings, there was a significant correlation $(r=.710, p=.001)$ between the absolute distance and the time when spontaneous activity was decreased by at least $50 \%$. This relationship held separately for the 11 recordings in the non-auditory RE $(r=.681, p=.02)$ and for the 17 recordings in the auditory RE $(r=.819, p<.0001)$.

As explained in the Introduction, the decreased activity observed in RE after NBM inactivation cannot be mediated by physiological effects. It most likely resulted from muscimol diffusion into the RE, even into the most caudal aspect of the RE (more than $1 \mathrm{~mm}$ away in antero-posterior distance, more than $2 \mathrm{~mm}$ away in absolute distance).

\section{Muscimol Injection in the Auditory RE: Recording in the MGB}

In 37 animals, muscimol was injected into the auditory RE at sites where short-latency tone-evoked responses were obtained from the electrodes glued to the guide tube. 


\section{Injection of $0.4 \mu \mathrm{l}$ in the NBM}
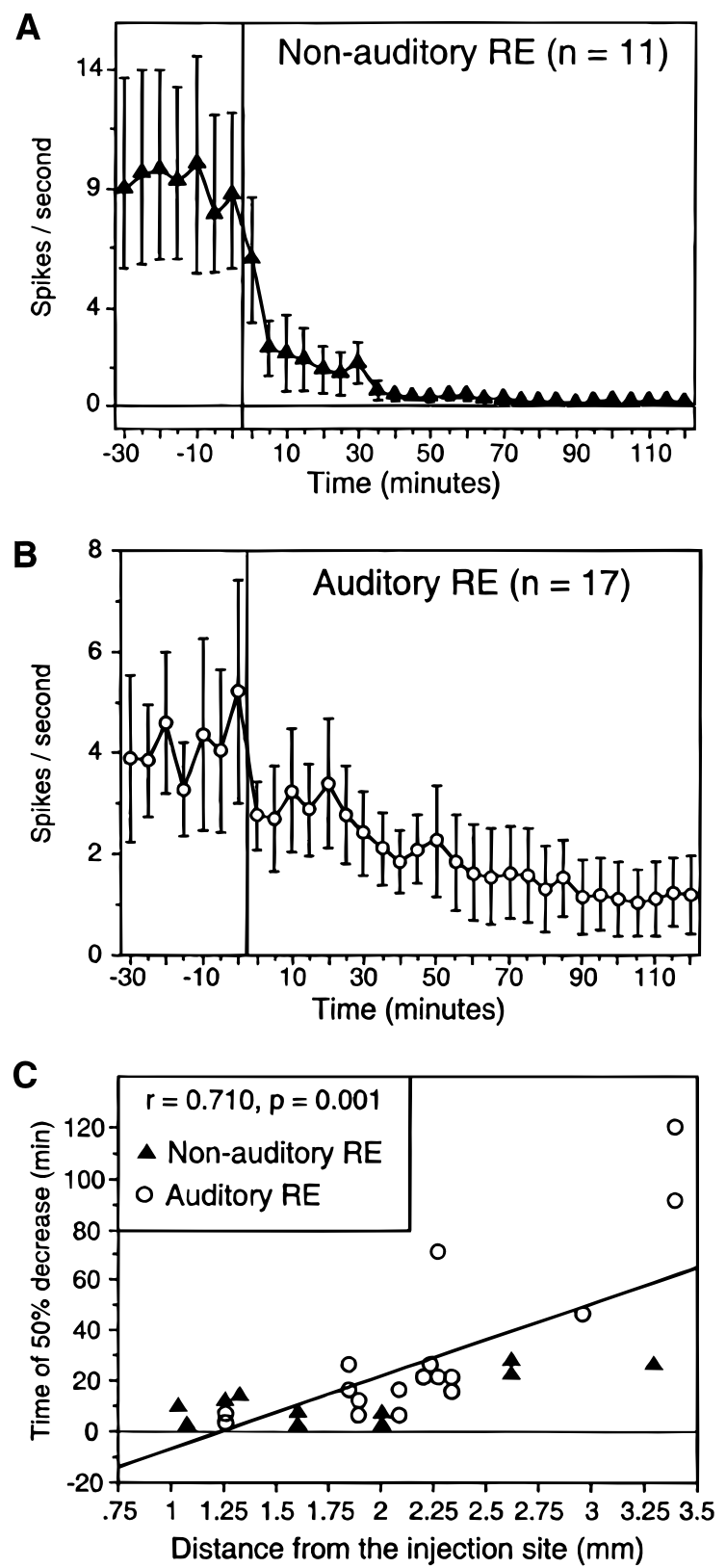

FIG. 2. Evolution of spontaneous activity in the reticular nucleus (RE) after $0.4-\mu l$ muscimol injection into the nucleus basalis magnocellularis (NBM). Spontaneous activity was recorded every 5 min during the 30 min preceding and the $120 \mathrm{~min}$ following muscimol injection. (A) For recordings collected in non-auditory sectors of the RE (the closest from the injection site), spontaneous activity (means $\pm S E M$ ) was largely attenuated in $10 \mathrm{~min}$, and it nearly fell to zero in $45 \mathrm{~min}$. (B) For recordings collected in the auditory sector of the RE (the farthest from the injection site), spontaneous activity dropped only slightly during the first $30 \mathrm{~min}$ following injection, and then it slowly decreased over time. (C) For each recording included in panels A and B, the time when spontaneous activity was decreased by at least $50 \%$ was plotted as a function of the absolute distance (see Materials and Methods) between the injection and recording sites. The significant correlation found between these two variables, and the fact that the decrease in activity cannot be explained by physiological mechanisms (see Introduction), suggests a passive diffusion of muscimol over time. 
Injection of $0.1 \mu \mathrm{l}$. The mean rostrocaudal distance between the injection site and the recording site was $2.30 \pm 0.08 \mathrm{~mm}$ (range : 1.4-2.9). The mean absolute distance was $2.57 \pm 0.42 \mathrm{~mm}$ (range : 1.7-3.1). The kinetics of changes in spontaneous and evoked activities in the MGB are presented in Fig. 3A. During the first 15 min after injection, spontaneous activity was slightly increased, $t(27)=1.377, p=.17$. It began to decrease during the following $15 \mathrm{~min}, t(27)=3.33, p=.02$, and it remained significantly depressed until the end of the experiment. The "on" tone-evoked response became significantly lower than the mean preinjection value 30 to 45 min after injection, $t(27)=3.122$, $p=.004$. As shown in Fig. 3B, there was a signification correlation $(r=.677, p=.001)$

\section{Injection of $0.1 \mu$ l in the auditory RE}
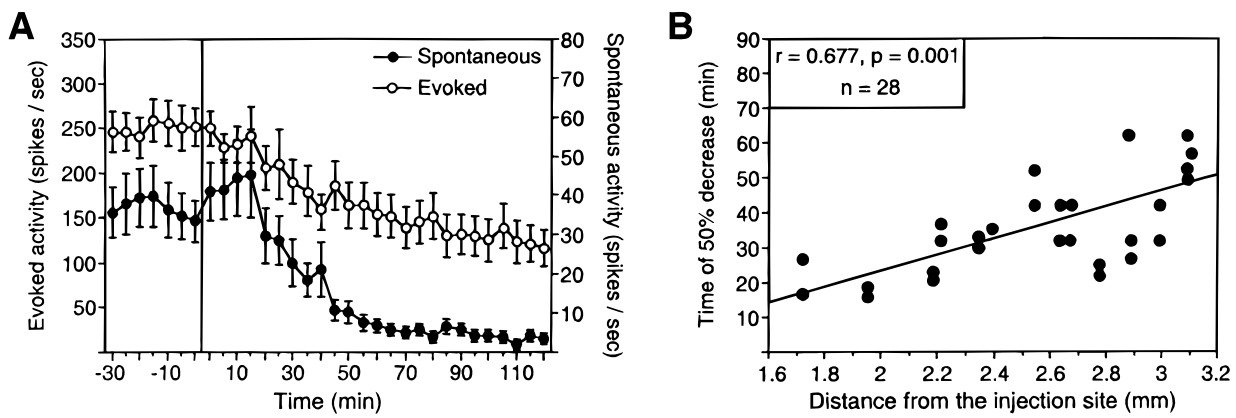

Injection of $0.05 \mu \mathrm{l}$ in the auditory RE
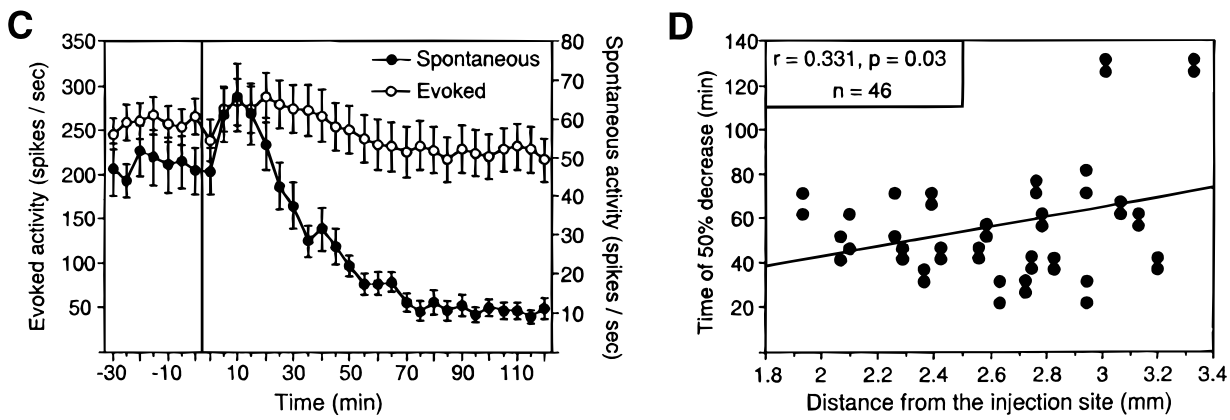

FIG. 3. Evolution of spontaneous and evoked activity in the medial geniculate body (MGB) after muscimol injection into the reticular nucleus (RE). Spontaneous and evoked activities were recorded every 5 min during the $30 \mathrm{~min}$ preceding and the $120 \mathrm{~min}$ following muscimol injection. (A) After injection of $0.1 \mu \mathrm{l}$, the spontaneous activity of MGB neurons was slightly increased during the first $15 \mathrm{~min}$, and then it started to decrease, reaching an asymptotic low level in about $60 \mathrm{~min}$. The tone-evoked response became significantly lower than the mean preinjection value 30 to $45 \mathrm{~min}$ after injection; it was reduced by $50 \%$ after $2 \mathrm{~h}$. (B) The time when spontaneous activity was decreased by at least $50 \%$ was plotted as a function of the absolute distance between the injection and recording sites. The significant correlation found between these two variables, and the fact that the decrease in activity cannot be explained by physiological mechanisms (see Introduction), suggests a passive diffusion of muscimol over time. (C) After injection of $0.05 \mu \mathrm{l}$, the spontaneous activity of MGB neurons was significantly increased during the first $15 \mathrm{~min}$, an effect that was expected given the well-known inhibitory action of RE neurons onto thalamic relay cells. After this period, spontaneous activity started to decrease, reaching an asymptotic low level in about $75 \mathrm{~min}$. The tone-evoked response was not significantly affected. (D) A significant correlation was found between the absolute distance and the time when spontaneous activity was decreased by at least $50 \%$. However, this correlation was due mainly to the fact that for four recording sites, located 3.0 to $3.4 \mathrm{~mm}$ away from the injection site, spontaneous activity was not decreased over the 2-h post-injection period. 
between the absolute distance and the time when spontaneous activity was reduced by at least $50 \%$.

Injection of $0.05 \mu \mathrm{l}$. The mean rostrocaudal distance between the injection and recording sites was $2.45 \pm 0.06 \mathrm{~mm}$ (range : 1.6-3.1). The mean absolute distance was $2.65 \pm 0.07 \mathrm{~mm}$ (range : 1.9-3.3). The evolution of spontaneous and evoked activities in the MGB are presented in Fig. 3C. During the first 15 min post-injection, spontaneous activity significantly increased, $t(45)=1.377, p<.01$. Thereafter, it progressively decreased; this decrease became significant $35 \mathrm{~min}$ after injection, $t(45)=3.33, p=.02$, and it remained such until the end of the experiment. Although it followed a comparable evolution, the "on" evoked response was not significantly affected.

Because GABAergic cells of the RE send a direct inhibitory input onto auditory thalamus cells (Crabtree, 1998; Montero, 1983), inactivation of the auditory sector of the RE should logically lead to increasing the spontaneous and evoked activity in the MGB. Thus, the increased neuronal activity observed in the MGB during the first minutes following injection most likely resulted from inactivation of RE cells. On the other hand, the decrease in spontaneous and evoked activity observed thereafter cannot be mediated by any known physiological effects. It likely resulted from muscimol diffusion into the MGB. Even some of the recordings collected in the most caudal aspect of the MGB (3 mm away in antero-posterior distance, $3.2 \mathrm{~mm}$ away in absolute distance) could be affected.

Altogether, these electrophysiological results led us to suspect that, in the case of both NBM and RE injections, muscimol diffused over time and suppressed neuronal activity at large distances $(2-3 \mathrm{~mm})$ from the injection site, even when a volume as small as $0.05 \mu \mathrm{l}$ was injected.

\section{Autoradiographic Results}

Autoradiographic experiments were carried out to have direct visualization and quantification of muscimol diffusion. For each animal $(n=25)$, the anteriority of the injection site was determined based on Nissl sections, and autoradiographic measures were taken up to more than $3 \mathrm{~mm}$ away from this anteriority.

\section{Quantification by Optical Density Measures}

The extent of muscimol diffusion in the three dimensions of space was estimated by measuring the height and width of the labeled area at the injection site and the rostrocaudal extent of diffusion. As shown in Fig. 4, the smallest values of height, width, and rostrocaudal extent were found in rats injected with $0.05 \mu \mathrm{l}$ in RE and sacrificed 15 min later. On average, for these animals, the half-height of the labeled area at the injection site was $1.10 \mathrm{~mm}$, the half-width was $1.14 \mathrm{~mm}$, and the rostrocaudal extent of diffusion was $1.7 \mathrm{~mm}$. All of these values were larger when the injected volume or the time between injection and sacrifice was increased. For example, when the survival time was increased from 15 to $60 \mathrm{~min}$ (Fig. 4A), the half-height reached $1.62 \mathrm{~mm}$, the half-width $1.66 \mathrm{~mm}$, and the rostrocaudal extent $2.2 \mathrm{~mm}$. This large extent of muscimol diffusion did not result from the fact that injection was made by hand. Indeed, comparable results were obtained after hand and pump injection (Fig. 4B). After pump injection, the height of the labeled area at the injection site was even larger (half-height: 1.91 vs $1.33 \mathrm{~mm}, p=.02$ ); the 


\section{A. $0.05 \mu$ l injection in RE : 15 vs 60 minutes}

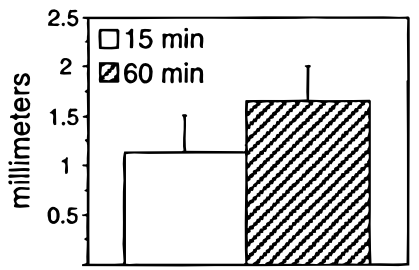

$1 / 2$ width

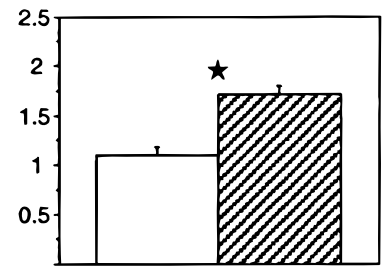

$1 / 2$ height

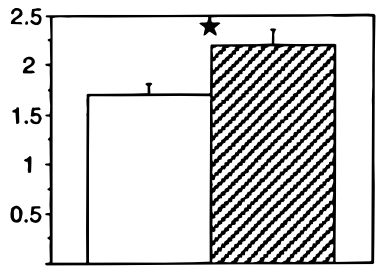

antero-post

\section{B. $0.1 \mu$ injection in RE : hand vs pump}

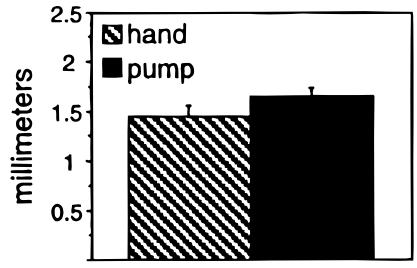

$1 / 2$ width

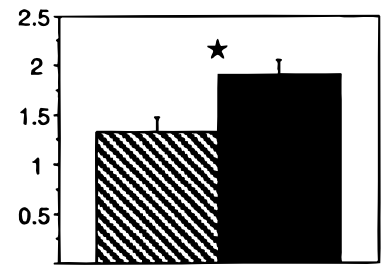

$1 / 2$ height

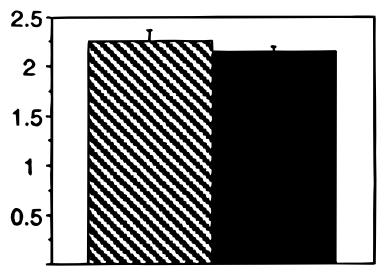

antero-post

\section{C. $0.1 \mu$ pump injection : NBM vs $\mathrm{RE}$}

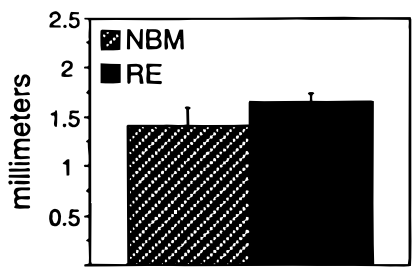

$1 / 2$ width

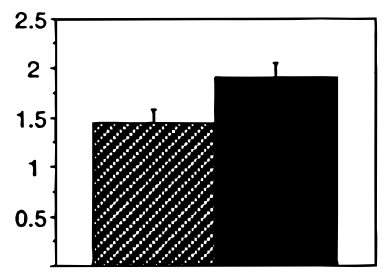

$1 / 2$ height

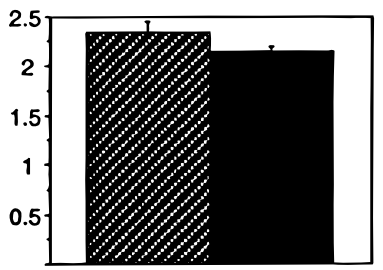

antero-post

FIG. 4. Maximal extent of muscimol diffusion in the three dimensions of space, as estimated by optical density measures from autoradiograms. The height and width (see Materials and Methods) of the labeled area at the injection site, as well as the antero-posterior extent of diffusion (radius value), were quantified for each rat. Data corresponding to a given group were averaged, and the results (means $\pm S E M$ ) are displayed by comparing pairs of groups. (A) After a survival time of $60 \mathrm{~min}$, the width and height of the labeled area at the injection site, as well as the antero-posterior extent of diffusion, were larger than they were after a survival time of $15 \mathrm{~min}$. (B) After pump injection, the height of the labeled area at the injection site was larger than it was after hand injection. The other two measures did not significantly differ between the two conditions. (C) After injection into the RE, the height of the labeled area at the injection site tended to be larger than it was after injection into the NBM $(p=.056)$. The other two measures did not significantly differ between the two conditions. ${ }^{*} p<.05$ (unpaired $t$ test).

other two measures did not significantly differ (lowest $p$ value $=.18$ for the width). Furthermore, this large diffusion was not specific to injections made in the RE given that comparable results ( $p=.056$ for the height, and $p>.21$ for the other two measures) were obtained when injections were made in the NBM (Fig. 4C).

Figure 5 shows the evolution of the labeled areas as a function of the distance from the injection site. The mean area measured at the injection site varied from $5.25 \mathrm{~mm}^{2}$ (for rats sacrificed $15 \mathrm{~min}$ after injection of $0.05 \mu \mathrm{l}$ in RE) to $12 \mathrm{~mm}^{2}$ (for rats injected with $0.1 \mu \mathrm{l}$ in RE via a pump). In all groups, the surface of the labeled zones progressively 
A. $0.05 \mu$ injection in RE : 15 vs $60 \mathrm{~min}$

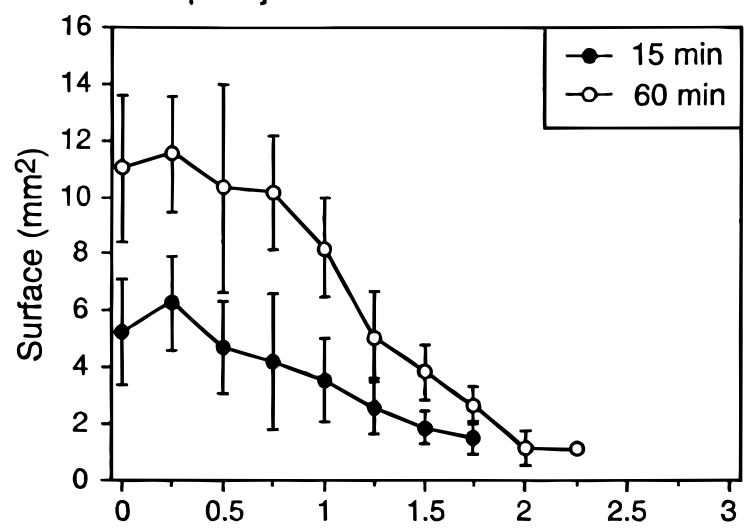

B. $0.1 \mu$ injection in RE : hand vs pump

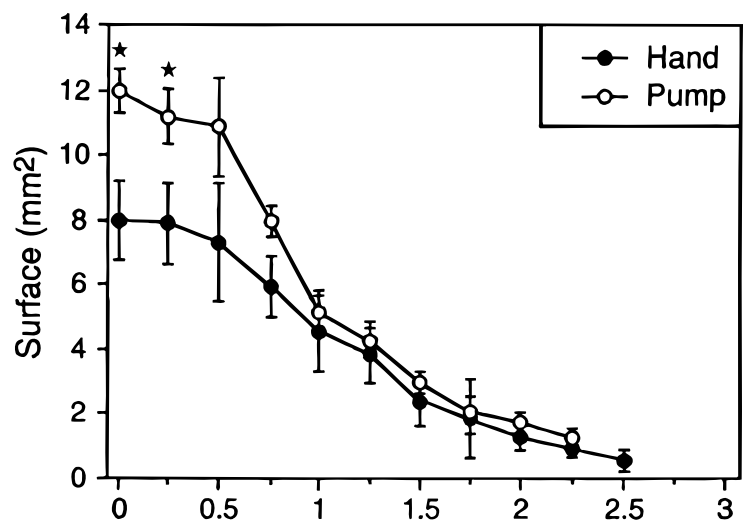

C. $0.1 \mu$ l pump injection : NBM vs RE

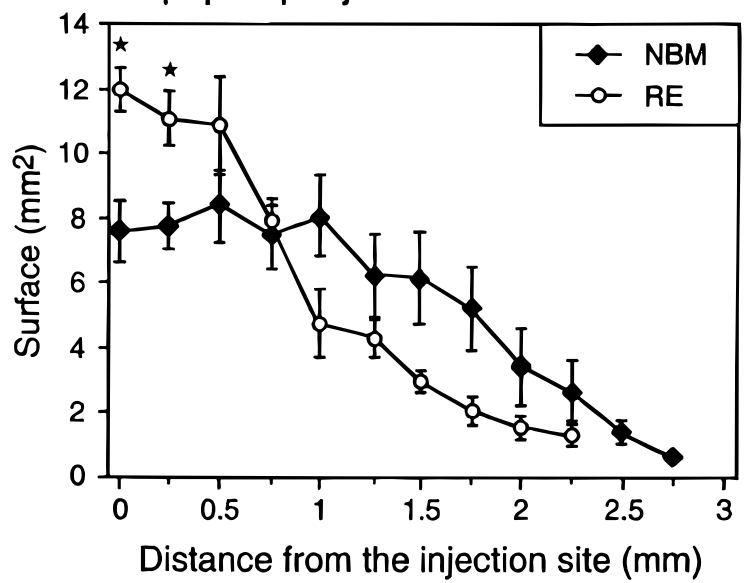

FIG. 5. Evolution of the surface of the labeled areas as a function of the distance from the injection site as estimated by optical density measures from autoradiograms. For each animal, the surface of the labeled areas was measured at given distances from the injection site. Data corresponding to a given group were pooled together, and surface profiles were constructed. Results (means $\pm S E M$ obtained from autoradiograms on which a labeled area could be measured) are displayed by comparing pairs of experimental groups. Analyses of variance indicated that for each pair comparison performed in panel A, B, or C, there was no significant effect of group 
decreased as the distance from the injection site increased. As shown in Fig. 6, the intensity of labeling also progressively decreased, in all groups, as a function of the distance. As could be expected, there was an inverse relationship between the surface of the labeled zone and the radioactivity value obtained in that zone (at least when the data were from the same brain area). The labeled areas were smaller in rats sacrificed $15 \mathrm{~min}$ after injection than in those sacrificed 60 min after injection (Fig. 5A), but the labeling values were higher in the former than in the latter (Fig. 6A). Similarly, the surface areas were smaller but the labeling was higher in rats injected by hand than in those injected by pump (Figs. 5B and 6B). The reason for this inverse relationship is quite trivial: When a given number of molecules diffuses in a larger volume of cerebral tissue, their concentration at a given site is lower.

Thus, OD measures indicated that $1 \mathrm{~h}$ after $0.1-\mu \mathrm{l}$ injection (whether made by hand or by pump in the RE or in the NBM), muscimol diffused, on average, up to at least $2.25 \mathrm{~mm}$ away from the injection site. Even when it was injected in a volume as small as $0.05 \mu \mathrm{l}$, its rostrocaudal diffusion reached, on average, $1.7 \mathrm{~mm}$ after $15 \mathrm{~min}$ and $2.2 \mathrm{~mm}$ after $60 \mathrm{~min}$. Because OD measures have limitations, especially when they are performed close to film background level, a second quantification was performed using a $\beta$-imager to better delineate the rostrocaudal extent of diffusion.

\section{Direct Measurement of the Radioactivity by a $\beta$-Imager}

A total of 122 brain sections from 20 rats were quantified by a $\beta$-Imager 2000 using a 21-h exposure time. For each animal, the last sections around which labeling disappeared according to OD measures were analyzed (see examples provided in Fig. 7). As shown from the group data in Fig. 8, this direct quantification of the radioactivity totally confirmed the wide spread of muscimol diffusion. It even revealed that the rostrocaudal extent of diffusion was larger than it had been estimated based on OD measures. Indeed, for every rat, radioactivity above the background level of the apparatus $(0.07$ counts $/ \mathrm{min})$ was still detected in sections that were 0.25 to $0.75 \mathrm{~mm}$ farther away than those from which labeling became undetectable with OD measurements.

\section{Additional Observations}

Autoradiographic results obtained from 5 rats injected with $0.4 \mu \mathrm{l}$ of muscimol in the NBM and sacrificed 120 min later are shown in Fig. 9. This group cannot be directly compared to any of the other groups; rats received the same amount of radioactive molecules as those injected with $0.1 \mu \mathrm{l}$, but these molecules were injected in a larger volume and the post-injection survival time was longer. Nonetheless, some observations from this group deserve to be mentioned. First, this group exhibited the lowest intensity of labeling at the injection site (for all comparisons with each of the other groups, $p<.020$ ).

(all p's > .09), but there was a significant effect of distance (all $p$ 's $<.0001$ ) and a significant Group $\times$ Distance interaction (all $p$ 's $<.005$ ). As could be expected, the smallest surfaces were found in rats injected with $0.05 \mu \mathrm{l}$ and sacrificed 15 min later. However, note that even in these animals, labeled areas could be measured up to $1.75 \mathrm{~mm}$ from the injection site. In all of the other groups, labeled areas could be measured farther away $(2.2-2.7 \mathrm{~mm}) .{ }^{*} p<.05$ (comparison at a given distance, unpaired $t$ test). 
A. $0.05 \mu$ injection in RE : 15 vs 60 min

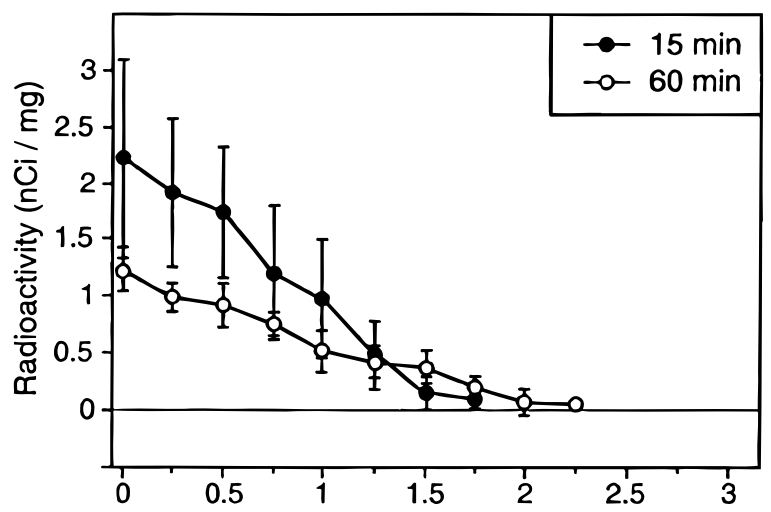

B. $0.1 \mu$ injection in $\mathrm{RE}$ : hand vs pump

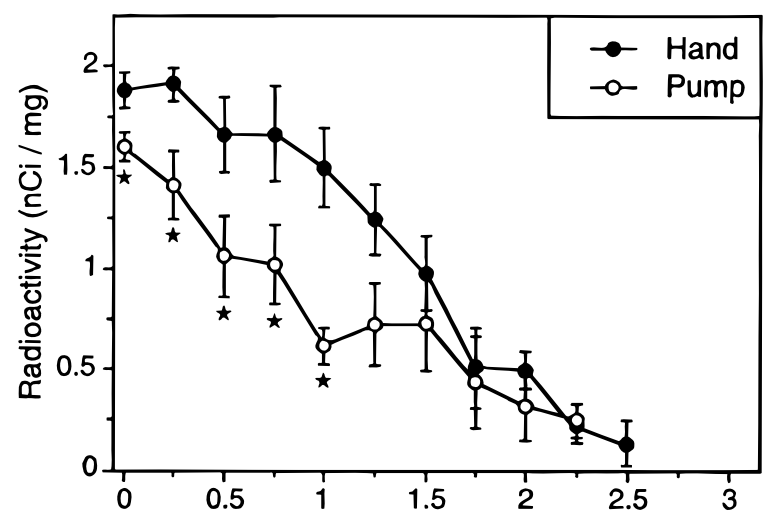

C. $0.1 \mu$ l pump injection : NBM vs RE

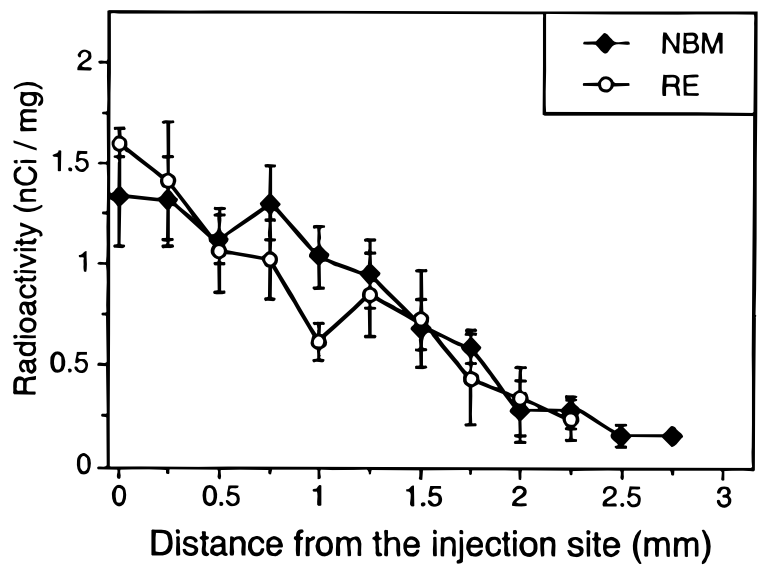

FIG. 6. Radioactivity profiles as estimated by optical density (OD) measures from autoradiograms. For each animal, the OD measure obtained from the area labeled at each distance from the injection site (see Fig. 5) was converted into level of radioactivity (see Materials and Methods). Data corresponding to a given group were pooled together, and radioactivity profiles were constructed. Results are displayed by comparing pairs of experimental groups. Analyses of variance indicated that for each pair comparison performed in panel A or B, there was no significant effect of group ( $p>.102$ in both cases), but there was a significant effect of distance $(p<.0001)$ and a significant Group $\times$ Distance interaction $(p<.01$ in both cases). For the two groups compared in panel $\mathrm{C}$, there was only a significant effect of distance $(p<.0001)$. Conventions are as in Fig. 5 . 
Injection of $0.1 \mu \mathrm{I}$

in RE

$2.25-3.0$

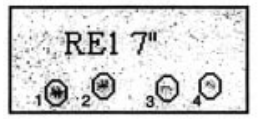

$2.0-2.75$

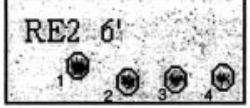

$1.75-2.5$

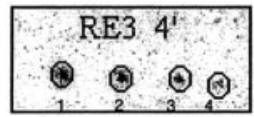

$2.0-2.75$

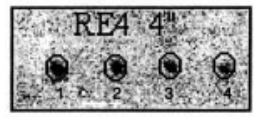

$1.75-2.5$

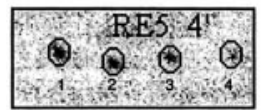

Injection of $0.1 \mu$ I in NBM

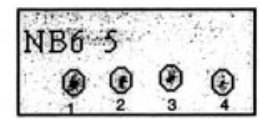

$2.5-3.25$

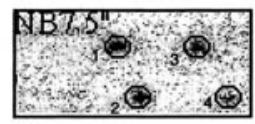

$1.75-2.5$

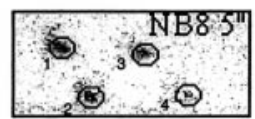

$2.25-3.0$

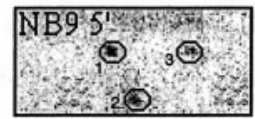

$2.5-3.0$

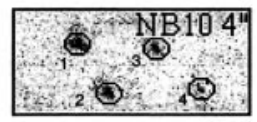

$2.25-3.0$

FIG. 7. Direct visualization of the radioactivity by the $\beta$-Imager 2000 for the brain sections the farthest away from the injection site. Data are from animals injected with $0.1 \mu$ l into the RE (RE1-RE5, Group 4 in Table 2) and from animals injected with $0.1 \mu$ into the NBM (NB6-NB10, Group 2 in Table 2). Each rectangle corresponds to the glass slide containing the last sections (20 $\mu \mathrm{m}$ thickness) available for each animal. There were four brain sections on each glass slide (except for rat NB9, for which only three brain sections were present). The area delimited on each section represents the constant surface from which the radioactivity was counted after $21 \mathrm{~h}$ of exposure. The numbers on the side of each rectangle indicate the distances from the injection site in millimeters. Scale bar at bottom right $=8.125 \mathrm{~mm}$.

Second, OD measures indicated that for each of the 5 rats in this group, labeling was still present at 2.7 to $3.1 \mathrm{~mm}$ from the injection site, which was the case for none of the other groups.

Quantification by the $\beta$-imager (19 sections from this group were analyzed) confirmed that this group exhibited the largest rostrocaudal extent of diffusion. Compared to rats injected with $0.1 \mu \mathrm{l}$ (which received the same amount of radioactive molecules), the levels of radioactivity found in this group at $2.5,2.7$, and $2.9 \mathrm{~mm}$ from the injection site were significantly higher ( $p$ 's $=.05, .020$, and .011 , respectively). Thus, these data confirm that increasing the injection volume and the post-injection survival time increases the extent of muscimol diffusion. In addition, they bring support to the electrophysiological data showing that $2 \mathrm{~h}$ after its injection, muscimol was still able to inactivate neuronal activity in regions located far from the injection site.

\section{DISCUSSION}

\section{Overview of the Results}

Using an injection volume $(0.05-0.4 \mu \mathrm{l})$ and a drug concentration $(1 \mu \mathrm{g} / \mu \mathrm{l}, 8.7 \mathrm{mM})$ in the range of those commonly employed in the literature, it appeared that neuronal activity was suppressed in the RE after muscimol injection into the NBM and was suppressed in the MGB after injection into the RE. In both cases, this decreased activity 

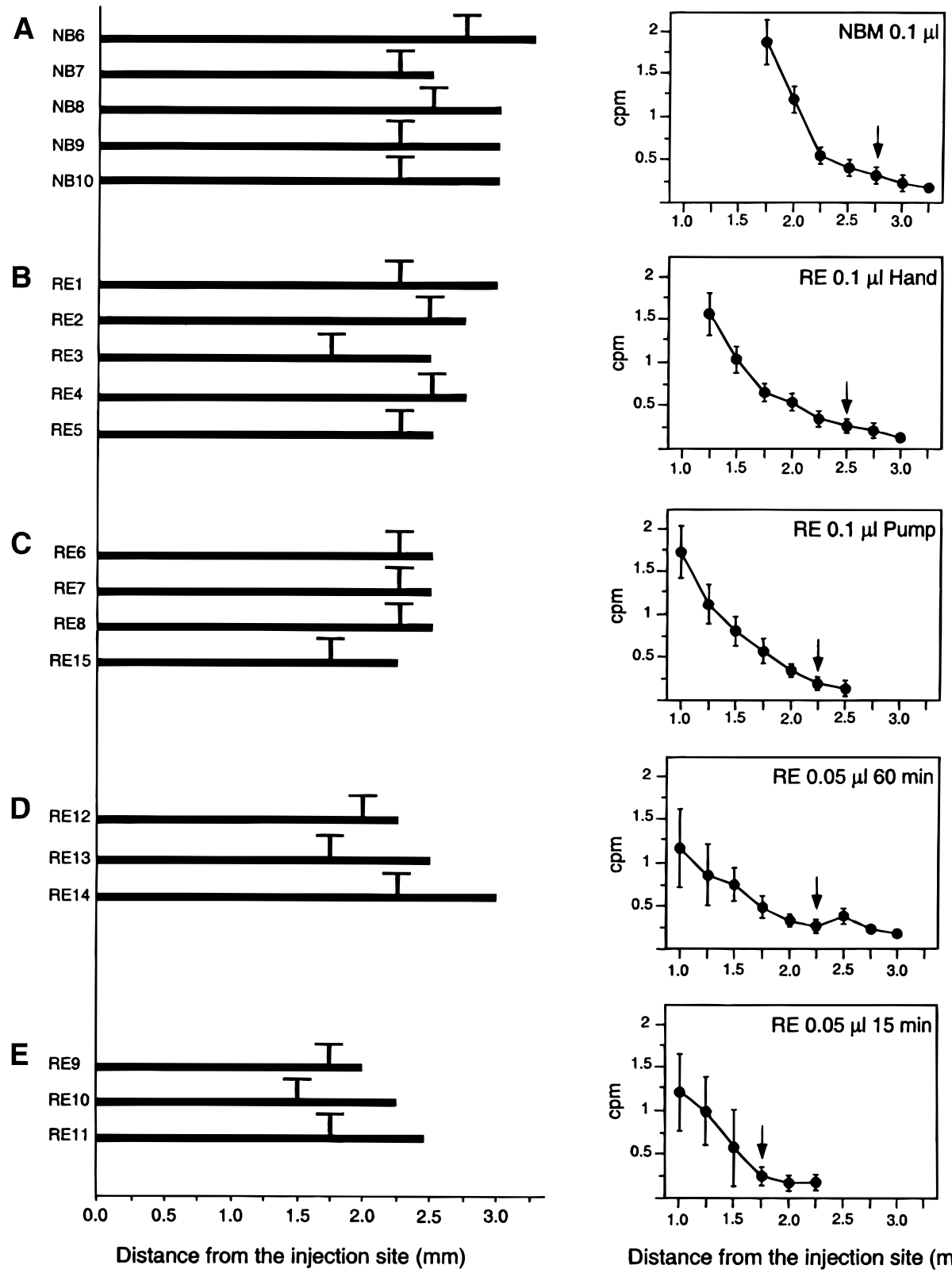

Distance from the injection site $(\mathrm{mm})$

FIG. 8. Comparison between the rostrocaudal extent of diffusion estimated by optical density (OD) measures and the one estimated by direct quantification of the radioactivity by the $\beta$-Imager 2000 . On the left side, the rostrocaudal extent of $\left[{ }^{3} \mathrm{H}\right]$ muscimol detected by the $\beta$-imager (see Materials and Methods) is represented, for each animal of each group, by the length of the thick black bar. The vertical ticks on these bars mark the rostrocaudal extent of $\left[{ }^{3} \mathrm{H}\right]$ muscimol diffusion estimated from OD measurements. Note that the $\beta$-imager systematically indicated a diffusion that extended beyond OD measures by 250 to $750 \mu \mathrm{m}$. The curves on the right side show the radioactivity values in counts per minute (means $\pm S E M$ ) obtained, for each group, as a function of the distance from the injection site. For each group, the arrow indicates the last distance where OD measures still detected $\left[{ }^{3} \mathrm{H}\right]$ muscimol. The experimental conditions for each group are detailed in Table 2 . Conventions are as in Fig. 5. 

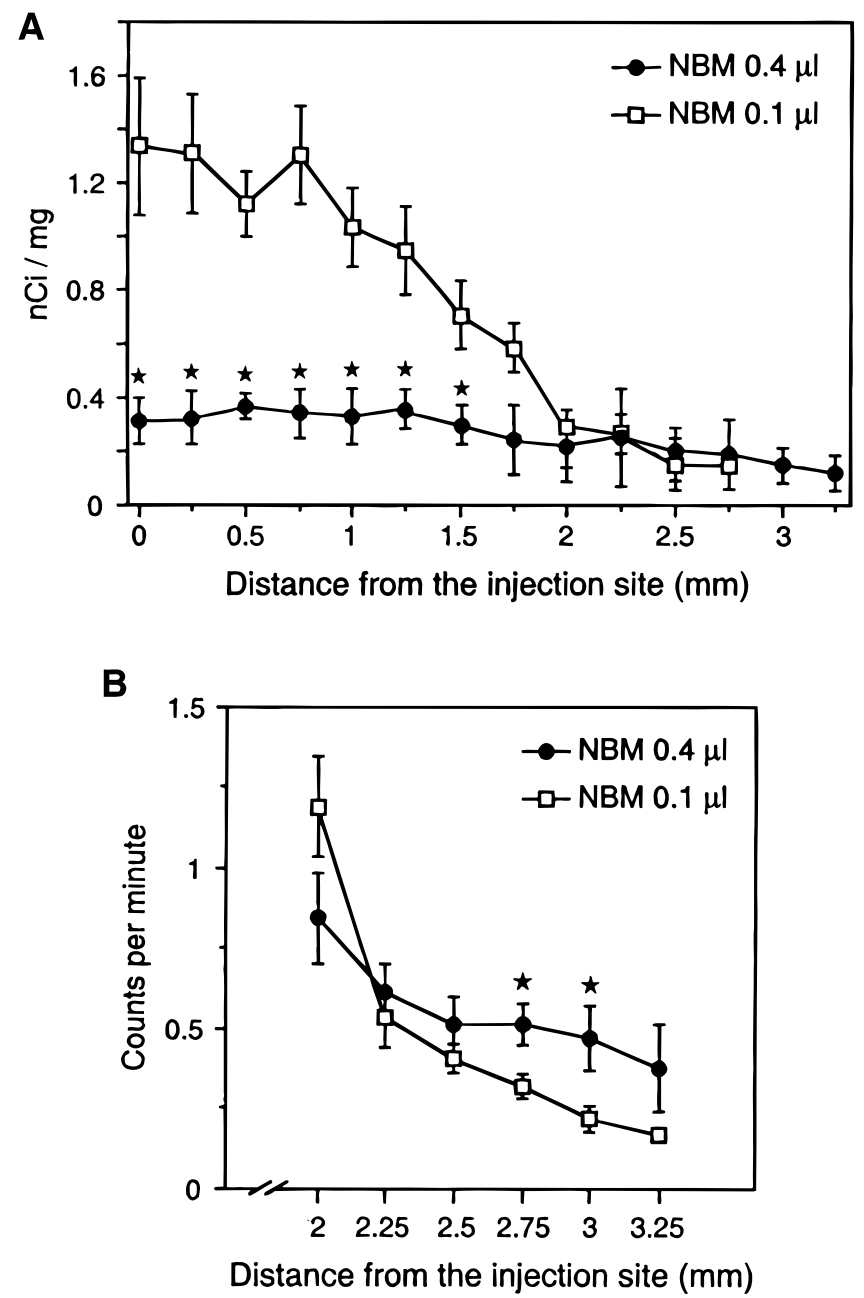

FIG. 9. Comparison of the radioactivity profiles obtained in the groups injected with 0.4 or $0.1 \mu \mathrm{l}$ of muscimol into the NBM. Rats in the $0.4-\mu$ l group were injected with $0.1 \mu \mathrm{l}$ of $\left[{ }^{3} \mathrm{H}\right]$ muscimol dissolved in $0.3 \mu \mathrm{l}$ of non-labeled muscimol and were sacrificed $2 \mathrm{~h}$ after injection. Thus, they received the same amount of radioactive molecules as did the group injected with $0.1 \mu \mathrm{l}$ of $\left[{ }^{3} \mathrm{H}\right]$ muscimol, but the injection volume was four times larger and the post-injection survival time was twice as long ( $2 \mathrm{~h}$ vs $1 \mathrm{~h}$ ). (A) Radioactivity profile estimated by optical density measures from autoradiograms. (B) Radioactivity profile estimated by direct quantification of the radioactivity with the $\beta$-imager. Note that up to $1.5 \mathrm{~mm}$ from the injection site, the intensity of labeling was largely attenuated in the $0.4-\mu$ l group (A). On the other hand, the amount of radioactivity counted on the most caudal sections analyzed was higher in this group (B). Conventions are as in Fig. 5.

cannot be explained by any known physiological effects, thereby suggesting a muscimol diffusion up to the recording sites. The widespread extent of muscimol diffusion was fully confirmed by autoradiographic results. Classical OD measures showed that $1 \mathrm{~h}$ after $0.1-\mu \mathrm{l}$ injection of $\left[{ }^{3} \mathrm{H}\right]$ muscimol in the NBM or in the RE, the labeled area extended up to 1.7 to $2.7 \mathrm{~mm}$ from the injection site, and $15 \mathrm{~min}$ after 0.05 - $\mu$ l injection, it already extended up to 1.4 to $1.7 \mathrm{~mm}$. More accurate measures obtained with a radioimager indicated that the diffusion of radioactive molecules was still larger $(0.25-0.75 \mathrm{~mm}$ farther away) than it had been estimated from OD measures. Whereas only minor differences were observed 
between hand and pump injections or between injections in the NBM and in the RE $(0.1 \mu \mathrm{l})$, the post-injection time seemed to be crucial. After $0.05-\mu$ l injection in the RE, the labeled area at the injection site was nearly twice as large at $60 \mathrm{~min}$ than at $15 \mathrm{~min}$, and the rostrocaudal extent of diffusion expanded by $0.5 \mathrm{~mm}$.

\section{Limitations and Validity of the Current Results}

It is first important to stress again the fact that the electrophysiological results obtained here were totally opposite to those expected on the basis of the known physiological mechanisms. As explained in the Introduction, increases in neuronal activity in the RE or in the MGB should have been expected after NBM or RE inactivation, respectively. Because we systematically observed decreased neuronal activity, we were forced to conclude that an unexpected large diffusion of muscimol was responsible for the observed effects. Thus, our experimental situation offers a considerable advantage: Whereas behavioral studies can only state whether or not muscimol injection in a brain region affects the studied behavior, we were in a situation where the direction of the effects was the signature either of real physiological effects or of real diffusion problems.

Second, no study had yet combined electrophysiological recordings and autoradiographic measures to estimate the extent of muscimol diffusion. In the past, only one study (Martin, 1991) has tried to relate muscimol diffusion and physiological effects, using $\left[{ }^{14} \mathrm{C}\right]$ glucose to assess changes in local cerebral glucose uptake. However, with this method it is not possible (a) to distinguish between the activity of afferent terminals, glial cells, and neurons and (b) to know whether hypometabolism observed at distance from the injection site reflects a reduction in cellular activity or in local cerebral blood flow. In addition, quantification of glucose use relies on autoradiogram analysis (i.e., on OD measurements that suffer from well-known pitfalls). In particular, the small dynamic range restricts the linear response, thereby preventing precise quantitative analysis for the high and, more problematic, for the low OD values. The electrophysiological technique is both more sensitive and more informative. Neuronal recordings can tell us whether, and when, the activity of neurons located at a given distance from the injection site is affected after drug injection. In the current experiment, they allowed us to state that the traces of muscimol detected by autoradiography far away from the injection site were effective and suppressed neuronal activity.

Lastly, it is obvious that the current study was not designed to investigate the numerous parameters that can affect muscimol diffusion. Such a study would require systematically using, for each investigated brain structure, a large range of volumes, drug concentrations and survival times. This was out of the scope of our initial objective.

\section{Comparison with Studies That Have Quantified Intracerebral Drug Diffusion}

Several studies have estimated the spread of drug diffusion after injection in various brain regions (Akaoka et al., 1992; Hupé, Chouvet, \& Bullier, 1999; Macklis \& Quattrochi, 1991; Martin, 1991; Myers, 1966; Myers \& Hoch, 1978; Routtenberg, 1972; Sandkühler, Maisch, \& Zimmermann, 1987; Tehovnik \& Sommer, 1997). Two of them are of particular relevance. Martin (1991) and Macklis and Quattrochi (1991) injected radiolabeled muscimol and carbachol, respectively, at cortical sites and quantified the radius of drug spread. 
Martin (1991) found a mean radius of $1.7 \mathrm{~mm}$ at $20 \mathrm{~min}$ post-injection (the volume injected was not provided). Macklis and Quattrochi (1991) found a radius of $1.5 \mathrm{~mm} 10$ min after a $0.05-\mu l$ injection. The results obtained here in rats injected with $0.05 \mu \mathrm{l}$ in $\mathrm{RE}$ and sacrificed 15 min later are compatible with those results; using classical OD measures, we found labeled zones up to $1.75 \mathrm{~mm}$ from the injection site. It may be noted, however, that the $\beta$-imager revealed traces of radioactivity up to $2.25 \mathrm{~mm}$.

An increasing spread of muscimol diffusion over time was first suspected in our experiment from the electrophysiological data. Because the time at which spontaneous activity decreased was a function of the distance from the injection site, we suspected that the drug slowly diffused in tissue and progressively reached more distant sites. In support of this, we found that, with both OD and radioactivity measurements, the rostrocaudal extent of muscimol diffusion increased over time; with $0.05 \mu \mathrm{l}$, it increased from $1.75 \mathrm{~mm}$ at $15 \mathrm{~min}$ to $2.25 \mathrm{~mm}$ at $60 \mathrm{~min}$ (according to OD measures). These results are at variance with those of Martin (1991), who reported that the maximal average radius $(1.7 \mathrm{~mm})$ was achieved within the first $20 \mathrm{~min}$ post-injection and remained constant over $2 \mathrm{~h}$. On the other hand, they are in good agreement with the results of Macklis and Quattrochi (1991), who described a radius enlargement from $1.5 \mathrm{~mm}$ at $10 \mathrm{~min}$ to 2.0 to $2.5 \mathrm{~mm}$ at $60 \mathrm{~min}$.

\section{Relationship with Studies on the Kinetics of Drug Diffusion}

For nearly 20 years, the works of Nicholson and colleagues have firmly established that the macroscopic laws of diffusion (Fick's laws) are closely obeyed in the central nervous system (CNS) (Nicholson, 1985; Nicholson \& Phillips, 1981; Vorisek \& Sykova, 1997; for a review, see Nicholson \& Sykova, 1998). As a consequence, the extent of diffusion is a function of the concentration gradient; the higher the initial concentration, the farther away a drug diffuses and the longer it takes to stop diffusing. Because muscimol is a potent ligand for $\mathrm{GABA}_{\mathrm{A}}$ receptors, much more so than GABA itself (KrogsgaardLarsen \& Johnston, 1978), it is only slowly displaced from its binding sites. Therefore, muscimol tends to spread until its concentration reaches equilibrium, that is, until the gradient of concentration equals zero. Given that the muscimol concentration used here, and in many behavioral studies, is relatively high $\left(8.710^{-3} \mathrm{M}\right)$, the time required to reach equilibrium is long.

Precise calculation of the extent of drug diffusion requires knowing the coefficient of diffusion $(D)$ of the drug as well as the volume fraction $(\alpha)$ and tortuosity $(\lambda)$ of the brain region. At the present time, the diffusion coefficient of muscimol has not yet been determined, nor have the volume fraction and tortuosity in NBM and in RE. However, using values determined (a) for molecules of similar molecular weight and (b) for other brain areas $\left(D=10^{-5} \mathrm{~cm}^{2} / \mathrm{s}, \alpha=0.2, \lambda=1.6\right.$ [see Nicholson \& Sykova, 1998]), we calculated that $1 \mathrm{~h}$ after a $0.1-\mu \mathrm{l}$ injection, the muscimol concentration at $2 \mathrm{~mm}$ from the injection site should be $310^{-3}$ lower than the initial one. This means that with an initial concentration of $8.710^{-3} \mathrm{M}$, the muscimol concentration is still $2.610^{-5} \mathrm{M}$. Such a concentration is far from being negligible; comparable or even lower concentrations have been used in some studies to inactivate the target structure and have been found to be effective in altering behavior (Givens \& Olton, 1994; Muir et al., 1992; Pang et al., 1993).

One should also be aware that the injected substance infiltrates the extracellular space 
(quantified by the volume fraction) and instantaneously (i.e., at a much shorter time scale than subsequent diffusion) spreads out to a radius larger than that naively expected based on the size of the droplet (Nicholson, 1985). Thus, the initial volume from which the drug starts diffusing is much larger than what is usually believed.

\section{Relationship with Behavioral Studies}

An important point to consider is to what extent the current findings square with those obtained in behavioral experiments that have used muscimol injections. The fact that the injected molecules diffuse is explicitly or implicitly recognized by any researcher using this technique. This is probably the reason why injection sites slightly outside the target nucleus ( $<500 \mu \mathrm{m}$ away) were considered acceptable (and gave results identical to those obtained with correct placements [Muller et al., 1997; Wilensky et al., 1999]). Furthermore, in some studies (Hardiman, Ramnani, \& Yeo, 1996; Ramnani \& Yeo, 1996), muscimol was deliberately injected at some distance $(0.5-1.0 \mathrm{~mm})$ from the target nucleus (to preserve the integrity of the structure) and $1 \mathrm{~h}$ before training (to allow drug diffusion). That leaves the obvious question: Up to what distance can muscimol diffusion affect behavioral responses? One way of answering this question is to determine the location of ineffective injection sites. In rabbits, using a volume of $1 \mu l$, injections as far as 2.5 $\mathrm{mm}$ apart were capable of affecting performance (Bracha, Webster, Winters, Irwin, \& Bloedel, 1994), whereas ineffective sites were found $3.2 \mathrm{~mm}$ away from the target structure (Hardiman et al., 1996). In rats, using $0.5 \mu \mathrm{l}$ but a concentration five times lower than ours, Meloni and Davis (1999) found that injections made $2 \mathrm{~mm}$ dorsal to the effective sites produced no behavioral effects (most superficial vs deepest layers of the superior colliculus); the location of ineffective sites in other directions was not reported. Interestingly, ineffective placements are often found dorsal to the effective ones (Hardiman et al., 1996; Krupa \& Thompson, 1997; Ramnani \& Yeo, 1996; Schmied, Amalric, Dormont, \& Farin, 1990, 1991), which might reflect the fact that drugs tend to preferentially go up along the cannula track (Hupé et al., 1999; Routtenberg, 1972). Lastly, two experiments looking at the effects of cerebellum inactivation in the nictitating membrane conditioning have reported both the location of ineffective placements and autoradiographic results (Krupa \& Thompson, 1997; Krupa, Weng, \& Thompson, 1996). Using 0.1 or $0.4 \mu$ l, three non-dorsal ineffective sites were found, slightly ventral or rostral to the effective ones, within the sphere of $\left[{ }^{3} \mathrm{H}\right]$ muscimol spread. The locations of the two ineffective ventral sites are rather puzzling given that the size of the injected muscimol droplet (radius of $457 \mu \mathrm{m}$ for $0.4 \mu \mathrm{l}$ and of $288 \mu \mathrm{m}$ for $0.1 \mu \mathrm{l}$ ) encompassed the distance between these sites and the target nucleus (see Krupa et al., 1996, Fig. 2; Krupa \& Thompson, 1997, Fig. 3). The third ineffective site was about $1 \mathrm{~mm}$ anterior of the target nucleus (injection of $0.4 \mu \mathrm{l}$ ). From these data, we cannot totally exclude the possibility that the effective spread of muscimol in terms of behavioral effects is smaller than the one revealed by autoradiographic measures. The decreases in spontaneous neuronal activity observed in the current study indicate that muscimol can have physiological effects far away from the injection site. However, if some neuronal responsiveness is preserved (although attenuated, evoked activity was still present [see Fig. 3]), behavioral responses might still be elicited at presentation of a conditioned stimulus.

Obviously, the apparent spread of muscimol is determined by the sensitivity of the 
methods employed to detect it (e.g., classical autoradiographic measurements vs direct counting of radioactivity). Similarly, the estimation of the "effective spread" is directly related to the dependent variable that is measured. Neuronal evoked activity seems to be more robust than spontaneous activity, and behavioral measures might be more robust than electrophysiological measures. However, we have to keep in mind that "more robust" probably goes hand in hand with "less sensitive."

The current study stresses the fact that muscimol diffusion is much larger than commonly supposed. Low drug concentrations and small injection volumes are probably the best way of limiting this diffusion. Also, as diffusion continues to progress for a long time after injection, it is critical to test the animal during the first minutes following injection. It is likely that these conclusions are generally applicable to other brain regions and other drugs because the diffusion of any molecules in the CNS follows the macroscopic laws of diffusion (see Nicholson \& Sykova, 1998). However, in practice, diffusion differs depending on the geometic parameters of the target brain area, the diffusion coefficient of the molecule used, its relative binding strength, and metabolic turnover (including uptake and degradation). To illustrate the diversity of factors influencing drug diffusion, recent electrophysiological data have shown that, despite comparable molecular weight, lidocaine and tetrodotoxin exhibited quite different time courses and effective spreads when delivered via microdialysis in the same brain area (Boehnke \& Rasmusson, 2001). These data and those of the current study stress the need for further studies quantifying the diffusion spread of inactivating agents. This type of investigation should be encouraged, not to deny the interest of the reversible inactivation technique for examining the neural basis of behavior, but rather to specify its limitations and hopefully to contribute to its future improvement.

\section{REFERENCES}

Akaoka, H., Saunier, C. F., Chergui, K., Charlety, P., Buda, M., \& Chouvet, G. (1992). Combining in vivo volumecontrolled pressure microejection with extracellular unit recording. Journal of Neuroscience Methods, 42, 119-128.

Ben-Ari, Y., Dingledine, R., Kanazawa, I., \& Kelly, J. S. (1976). Inhibitory effects of acetylcholine on neurones in the feline nucleus reticularis thalami. Journal of Physiology, 261, 647-671.

Beninger, R. J., Ingles, J. L., Mackenzie P. J., Jhamandas K., \& Boegman R. J. (1992). Muscimol injections into the nucleus basalis magnocellularis of rats: Selective impairment of working memory in the double Y-maze. Brain Research, 597, 66-73.

Boehnke, S. E., \& Rasmusson, D. D. (2001). Time course and effective spread of lidocaine and tetrodoxin delivered via microdialysis: An electrophysiological study in cerebral cortex. Journal of Neuroscience Methods, 105, 133-141.

Bracha, V., Webster, M. L., Winters, N. K., Irwin, K. B., \& Bloedel, J. R. (1994). Effects of muscimol inactivation of the cerebellar interposed dentate nuclear complex on the performance of the nictitating membrane response in the rabbit. Experimental Brain Research, 100, 453-468.

Charpak G., Dominik, W., \& Zaganidis, N. (1989). Optical imaging of the spatial distribution of beta-particles emerging from surfaces. Proceedings of the National Academy of Sciences (USA), 86, 1741-1745.

Charpak G., Imrie D., Jeanjean, J., Mine, P., Nguyen, H., Scigocki, D., Tavernier, S. P., \& Wells, K. (1989). A new approach to positron emission tomography. European Journal of Nuclear Medicine, 15, 690-693.

Cotillon, N., \& Edeline, J.-M. (2000). Tone-evoked oscillations in the rat auditory cortex result from interaction between the thalamus and reticular nucleus. European Journal of Neuroscience, 12, 3637-3650.

Crabtree, J. W. (1998). Organization in the auditory sector of the cat's thalamic reticular nucleus. Journal of Comparative Neurolology, 390, 167-182. 
Dudchenko, P., \& Sarter, M. (1991). GABAergic control of basal forebrain cholinergic neurons and memory. Behavioural Brain Research, 42, 33-41.

Givens, B., \& Olton, D. S. (1994). Local modulation of basal forebrain: Effects on working and reference memory. Journal of Neuroscience, 14, 3578-3587.

Hardiman, M. J., Ramnani, N., \& Yeo, C. H. (1996). Reversible inactivations of the cerebellum with muscimol prevent the acquisition and extinction of conditioned nictitating membrane responses in the rabbit. Experimental Brain Research, 110, 235-247.

Hikosaka, O., \& Wurtz, R. H. (1985). Modification of saccadic eye movements by GABA-related substances. I. Effects of muscimol and bicuculline in monkey superior colliculus. Journal of Neurophysiology, 53, $266-291$.

Hilles, B. (1966). Common mode of action of three agents that decrease the transient change in sodium permeability in nerves. Nature, 210, 1220-1222.

Hilles, B. (1977). The pH-dependent rate of action of local anesthetics on the node of Ranvier. Journal of General Physiology, 69, 475-496.

Holt, W., \& Maren, S. (1999). Muscimol inactivation of the dorsal hippocampus impairs contextual retrieval of fear memory. Journal of Neuroscience, 19, 9054-9062.

Houser, C. R., Vaughan, J. E., Barber, R. P., \& Roberts, E. (1980). GABA neurons are the major cell type of the nucleus reticularis thalami. Brain Research, 200, 341-354.

Hupé, J. M., Chouvet, G., \& Bullier, J. (1999). Spatial and temporal parameters of cortical inactivation by GABA. Journal of Neuroscience Methods, 86, 129-143.

Jones, E. G. (1975). Some aspects of the organization of the thalamic reticular complex. Journal of Comparative Neurology, 162, 285-308.

Jourdain, A., Semba, K., \& Fibiger, H. C. (1989). Basal forebrain and mesopontine tegmental projections to the reticular thalamic nucleus: An axonal collateralization and immunohistochemical study in the rat. Brain Research, 505, 55-65.

Krogsgaard-Larsen, P., \& Johnston, G. A. (1978). Structure-activity studies on the inhibition of GABA binding to rat brain membranes by muscimol and related compounds. Journal of Neurochemistry, 30, 1377-1382.

Krupa, D. J., Weng, J., \& Thompson, R. F. (1996). Inactivation of brainstem motor nuclei blocks expression but not acquisition of the rabbit's classically conditioned eyeblink response. Behavioral Neuroscience, 110, 219-227.

Krupa D. J., \& Thompson, R. F. (1997). Reversible inactivation of the cerebellar interpositus nucleus completely prevents acquisition of the classically conditioned eye-blink response. Learning and Memory, 3, 545-556.

Lanièce, P., Charon, Y., Cardona, A., Pinot, L., Maitrejean, S., Mastrippolito, R., Sandkamp, B., \& Valentin, L. (1998). A new high resolution radioimager for the quantitative analysis of radiolabelled molecules in tissue. Journal of Neuroscience Methods, 86, 1-5.

Macklis, J. D., \& Quattrochi, J. J. (1991). Restricted diffusion and stability of carbachol-fluorescent nanospheres in-vivo. NeuroReport, 2, 247-250.

Martin, J. H. (1991). Autoradiographic estimation of the extent of reversible inactivation produced by microinjection of lidocaine and muscimol in the rat. Neuroscience Letters, 127, 160-164.

Martin, J. H., \& Ghez, C. (1999). Pharmacological inactivation in the analysis of the central control of movement. Journal of Neuroscience Methods, 86, 145-159.

McCormick, D. A., \& Prince, D. A. (1986). Acetylcholine induces burst firing in thalamic reticular neurones by activating a potassium conductance. Nature, 319, 402-406.

Meloni, E. G., \& Davis, M. (1999). Muscimol in the deep layers of the superior colliculus/mesencephalic reticular formation blocks expression but not acquisition of fear-potentiated startle in rats. Behavioral Neuroscience, 113, 1152-1160.

Montero, V. M. (1983). Ultrastructural identification of axon terminals from the thalamic reticular nucleus in the medial geniculate body in the rat: An EM autoradiographic study. Experimental Brain Research, 51, 338-342. 
Muir, J. L., Robbins, T. W., \& Everitt, B. J. (1992). Disruptive effects of muscimol infused into the basal forebrain on conditional discrimination and visual attention: Differential interactions with cholinergic mechanisms. Psychopharmacology, 107, 541-550.

Muller, J., Corodimas, K. P., Fridel, Z., \& LeDoux, J. E. (1997). Functional inactivation of the lateral and basal nuclei of the amygdala by muscimol infusion prevents fear conditioning to an explicit conditioned stimulus and to contextual stimuli. Behavioral Neuroscience, 111, 683-691.

Myers, R. D. (1966). Injection of solutions into cerebral tissue: Relation between volume and diffusion. Physiology and Behavior, 1, 171-174.

Myers, R. D., \& Hoch, D. B. (1978). ${ }^{14}$ C-dopamine microinjected into the brain-stem of the rat: Dispersion kinetics, site content, and functional dose. Brain Research Bulletin, 3, 601-609.

Nagahara, A. H., Brioni, J. D., \& McGaugh, J. L. (1992). Effects of intraseptal infusion of muscimol on inhibitory avoidance and spatial learning: Differential effects of pretraining and posttraining administration. Psychobiology, 20, 198-204.

Nagahara, A. H., \& McGaugh, J. L. (1992). Muscimol infused into the medial septal area impairs long-term memory but not short-term memory in inhibitory avoidance, water maze place learning, and rewarded alternation tasks. Brain Research, 591, 54-61.

Nicholson, C. (1985). Diffusion from an injected volume of a substance in brain tissue with arbitrary volume fraction and tortuosity. Brain Research, 333, 325-329.

Nicholson, C., \& Phillips, J. M. (1981). Ion diffusion modified by tortuosity and volume fraction in the extracellular microenvironment of the rat cerebellum. Journal of Physiology, 321, 225-257.

Nicholson, C., \& Sykova, E. (1998). Extracellular space structure revealed by diffusion analysis. Trends in Neuroscience, 21, 207-215.

Oshiro, W. M., Bushnell, P. J., \& Chiba, A. A. (2000). A comparison of the effects of bilateral and unilateral infusions of muscimol into the basal forebrain on cued detection of visual targets in rats. Behavioral Neuroscience, 114, 137-149.

Pang, K., Williams, M. J., Egeth, H., \& Olton, D. S. (1993). Nucleus basalis magnocellularis and attention: Effects of muscimol infusions. Behavioral Neuroscience, 107, 1031-1038.

Paolini, A., Cotterill, E., Bairaktaris, D., \& Clark, G. M. (1998). Muscimol suppression of the dorsal cochlear nucleus impairs frequency discrimination in rats. Behavioural Brain Research, 97, 79-88.

Pinault, D., \& Deschenes, M. (1992). Muscarinic inhibition of reticular thalamic cells by basal forebrain neurones. NeuroReport, 3, 1101-1104.

Pinault, D., \& Deschenes, M. (1998). Anatomical evidence for a mechanism of lateral inhibition in the rat thalamus. European Journal of Neuroscience, 10, 3462-3469.

Poremba, A., \& Gabriel, M. (1999). Amygdala neurons mediate acquisition but not maintenance of instrumental avoidance behavior in rabbits. Journal of Neuroscience, 19, 9635-9641.

Ramnani, N., \& Yeo, C. H. (1996). Reversible inactivations of the cerebellum prevent the extinction of conditioned nictitating membrane responses in rabbits. Journal of Physiology, 495, 159-168.

Ritchie, J. M. (1979). A pharmacological approach to the structure of sodium channels in myelinated axon. Annual Review in Neuroscience, 2, 341-362.

Rouiller, E. M., \& Welker, E. (1991). Morphology of corticothalamic terminals arising from the auditory cortex of the rat: A Phaseolus vulgaris-leucoagglutinin (PHA-L) tracing study. Hearing Research, 56, 179-190.

Routtenberg, A. (1972). Intracranial chemical injection and behavior: A critical review. Behavioral Biology, 7, 601-641.

Sandkuhler, J., Maisch, B., \& Zimmermann, M. (1987). The use of local anaesthetic microinjections to identify central pathways: A quantitative evaluation of the time course and extent of the neuronal block. Experimental Brain Research, 68, 168-178.

Schmied, A., Amalric, M., Dormont, J. F., \& Farin, D. (1990). GABAergic mechanisms in the cat red nucleus: Effects of intracerebral microinjections of muscimol or bicuculline on a conditioned motor task. Experimental Brain Research, 81, 523-532.

Schmied, A., Amalric, M., Dormont, J. F., \& Farin, D. (1991). GABAergic control of rubral single unit activity during a reaction time task. Experimental Brain Research, 84, 285-296. 
Shosaku, A., \& Sumitomo, I. (1983). Auditory neurons in the rat thalamic reticular nucleus. Experimental Brain Research, 49, 432-442.

Smith, C. G., Beninger, R. J., Mallet, P. E., Jhamandas, K., \& Boegman, R. J. (1994). Basal forebrain injections of the benzodiazepine partial inverse agonist FG 7142 enhance memory of rats in the double Y-maze. Brain Research, 666, 61-67.

Tehovnik, E. G., \& Sommer, M. A. (1997). Effective spread and timecourse of neural inactivation caused by lidocaine injection in monkey cerebral cortex. Journal of Neuroscience Methods, 74, 17-26.

Vorisek, I., \& Sykova, E. (1997). Evolution of anisotropic diffusion in the developing rat corpus callosum. Journal of Neurophysiology, 78, 912-919.

Welsh, J. P., \& Harvey, J. A. (1991). Pavlovian conditioning in the rabbit during inactivation of the interpositus nucleus. Journal of Physiology, 444, 459-480.

Wilensky, A. E., Schafe, G. E., \& LeDoux, J. E. (1999). Functional inactivation of the amygdala before but not after auditory fear conditioning prevents memory formation. Journal of Neuroscience, 19, RC48 [Online].

Wilensky, A. E., Schafe, G. E., \& LeDoux, J. E. (2000). The amygdala modulates memory consolidation of fear-motivated inhibitory avoidance learning but not classical fear conditioning. Journal of Neuroscience, 20, 7059-7066. 